\title{
RELASI GENDER SACHIKO MURATA (ANALISIS FILSAFAT TAO DAN SPIRITUALITAS ISLAM)
}

\author{
Fatrawati Kumari \\ Jurusan Akidah Filsafat Fakultas Ushuluddin dan Humaniora \\ IAIN Antasari Banjarmasin \\ Jl. A. Yani Km 4,5 Banjarmasin
}

Diterima 10 Desember 2012/Disetujui 15 Juni 2013

\begin{abstract}
Thought -oriented feminism Indonesia with a Western perspective characteristic rational, materialistic and quantitative had been implicated in the occurrence of friction with the values in the eastern -oriented society that upholds harmonitas the characteristics, the spirituality, and the quality. Murata thought was based on Eastern perspective needed to be studied and received great attention, not only as an answer to the problems faced by the dominance of western orientation, but also as a counterweight to the tendency that the biassed too. Murata thought used the mystic Taoism and Islam, seeing the gender relations as relations dualist - complementary, relations two seemingly contradictory qualities, but it was one unit. The relationships found in all reality, include: people, nature and the God. Opposition of masculinity and femininity was not in the sense of separateness, but rather in the sense of unity, equality and reciprocity.
\end{abstract}

Kata kunci: relasi gender, filsafat Tao, spiritualitas Islam

\section{Pendahuluan}

Kajian tentang perempuan di Indonesia dalam beberapa dekade terakhir ini menampakkan perkembangan pesat. Pusat Studi dan Kajian Perempuan menjamur hampir di setiap Perguruan Tinggi, di kantor instansi pemerintah, maupun di masyarakat luas. Kesadaran akan perbaikan keadaan perempuan yang dipelopori oleh feminisme Barat telah memberi inspirasi bagi perempuan di seluruh dunia, termasuk di Indonesia. Perempuan - perempuan Indonesia dengan telah menunjukkan kiprahnya yang nyata dengan turut ambil bagian dalam arus tersebut. ${ }^{1}$ Beberapa persoalan berkembang dalam kajian gender,

${ }^{1}$ Fauzi Ridjal dkk. ed., Dinamika Gerakan Perempuan di Indonesia, (Yogyakarta: Tiara Wacana, 1993), cetakan pertama, 124-126. 
seperti: subordinasi (penomorduaan perempuan), marginalisasi (peminggiran perempuan) dan stereotipe (pelabelan negatif terhadap perempuan). ${ }^{2}$ Beberapa teori juga digunakan untuk menjelaskan problem dan hirarki gender yang menjadi penyebab ketidakadilan gender. ${ }^{3}$

Problem gender yang mencerminkan keadaan riil perempuan Indonesia yang cukup memprihatinkan, mendorong feminis untuk melakukan aksi nyata, di antaranya berupa penyadaran, pemberdayaan, pembuatan undang-undang, perlindungan, pembelaan hukum, pendampingan dan lain sebagainya. Apa yang dilakukan perempuan Indonesia telah seiring dengan spirit feminis seluruh dunia yang berupaya menempatkan perempuan secara setara, yaitu sebagai makhluk yang otonom sebagaimana laki-laki. ${ }^{4}$

Meski demikian, seluruh upaya feminis Indonesia tersebut tidak seluruhnya mendapat sambutan sebagaimana yang diharapkan. Ditemukan banyak ganjalan dan persoalan, diantaranya adanya anggapan, bahwa gerakan feminisme merupakan perpanjangan tangan dari ideologi patriarkal dari modernisasi yang sebelumnya dikritik oleh feminisme sendiri. ${ }^{5}$ Feminis dianggap telah melakukan universalisasi persoalan sebagaimana ideologi universal modern yang berlaku pada saat ini. Gagasan emansipasi yang merupakan hasil derivasi dari modernisasi memiliki karakteristik yang sama dengan rasionalitas modernisasi, yaitu

2 Mansour Fakih, Analisis Gender dan Transformasi Sosial, (Yogyakarta: Pustaka Pelajar, 1997), cetakan kedua, 154. Lihat pula, Budiman, Arif, Pembagian Kerja Secara Seksual, (Jakarta: Gramedia, 183), cetakan kedua, h.1-5. 1988), h.6

${ }^{3}$ Lihat Harietta L Moore, Feminism and Antropology, (Cambridge: Politiy Press,

${ }^{4}$ Lihat apa saja problem dalam: Fauzi Ridjal, dkk. ed., Dinamika Gerakan Perempuan di Indonesia, h. 80-84. Lihat bagaimana otonomi perempuan sebagai manusia dalam: Naomi Wolf, Gegar Gender, judul asli: Fire With Fire, alih bahasa: Omi Intan Naomi, (Yogyakarta: Pustaka Semesta Press, 1997), cetakan pertama, h. 339-340.

${ }^{5}$ Rebeka Harsono, "Gerakan Perempuan: Antara Kepentingan Perempuan dan Politik Gender," dalam: Irwan Abdullah, ed., Sangkan Paran Gender, (Yogyakarta: Pustaka Pelajar, 2006), 298-302. Lihat Tapi Omas Ihromi \& Luhulima, Achie, Hak Azazi Perempuan, Jakarta: Convention Watch, Pusat Kajian Wanita dan Gender UI \& Yayasan Obor Indonesia, 2003), h. 82-102. Lihat Arimbi Heroepoetri \& R. Valentina, Percakapan tentang Feminisme vs Neoliberalisme, (Jakarta: debtWATCH Indonesia - Institut Perempuan, 2004), h. 38-39. 
penguasaan manusia terhadap manusia lain dan penguasaan manusia terhadap alam. ${ }^{6}$

Konsep emansipasi yang diusung oleh feminis dan gerakan pencerahan Barat telah membuka praktek hegemoni dan dominasi di setiap lini masyarakat, baik oleh laki-laki atas perempuan, perempuan atas laki-laki, negara-negara maju terhadap negara miskin, maupun Barat terhadap Timur. Hagemoni dan dominasi yang berasal dari sistem patriarki dan modernisasi, ternyata juga dianut feminism sendiri. ${ }^{7}$ Emansipasi yang bertolak dari logika patriarki yang eksploitatif dan materialistis telah menempatkan diri sebagai pewaris tradisi patriarki. ${ }^{8}$ Para feminis turut serta dalam arus laki-laki dengan memandang manusia lain dan alam berada dalam posisi hirarkis dan antagonis, yaitu dengan memandang mereka sebagai "yang lain", "sesuatu yang berbeda", "objek" sekaligus sebagai "musuh". " Feminis mengikuti inti ajaran sejarah Hegel dan dialektika Marx yang menganggap perjuangan secara terus-menerus sebagai cara untuk bertahan dari kehidupan yang keras. Sejarah telah menunjukkan, bahwa paradigma gender berjalan seiring dengan perkembangan ilmu pengetahuan dan secara integral masuk ke dalam proyek modernisasi sehingga dengan demikian telah memberikan sumbangan yang signifikan terhadap kemapanan logika partiarki. ${ }^{10}$

Bertolak dari kenyataan tersebut, beberapa feminis terdorong untuk membangun model relasi baru yang tidak patriarkal, melainkan bersandar pada logika kesalingan yang menghubungkan manusia dengan manusia serta manusia dengan alam yang disebut dengan ekofeminisme. Kelompok yang menonjolkan feminitas ini menganggap semua manusia telah terstruktur dalam hubungan laten kesalingan dengan lingkungan sekitarnya. Individu didefinisikan secara holistik dengan segala aspek

${ }^{6}$ Lihat Vandana Shiva \& Maria Mies, Ekofeminisme: Presfektif Gerakan Perempuan dan Lingkungan, judul asli: Ecofeminsme, alih bahasa: Kelik Ismunanto dan Lilik, IRE Press, 2005), h. 12.

${ }^{7}$ Maggie Humm, Ensiklopedia Feminisme, judul asli: "Dictionary of Feminist Theory” alih bahasa Mundi Rahayu, (Yogyakarta: Fajar Pustaka Baru, 2003), cetakan pertama, h. 130.

${ }^{8}$ Rene Descartes, Discourse on Methode, (Chicago: The Opera Court Publishing Company, 1962), h. 24.

${ }^{9}$ Vandana Shiva \& Maria Mies, Ekofeminisme: Presfektif Gerakan Perempuan dan Lingkungan, h. 6.

${ }^{10}$ Ivan Illich, Matinya Gender, judul asli: Gender, alih bahasa: Omi Intan Naomi, (Yogyakarta: Pustaka Pelajar, 1998), cetakan pertama, h. 125. 
yang mengitarinya, meliputi manusia dan alam. ${ }^{11}$ Ekofeminisme menawarkan jalan keluar dengan memperhatikan aspek fundamental feminin manusia yang selama ini diabaikan, yaitu "hati". "Kepemimpinan hati" dengan pendekatan Timurnya, mampu menciptakan tatanan dunia baru yang lebih demokratis dan berkeadaban. ${ }^{12}$ Ekofeminisme menampilkan kesucian relasi manusia dengan membangun kembali kesucian kehidupan yang telah terabaikan. Bagi aliran ini, hanya dengan kesucian, kehidupan di muka bumi ini dapat dilestarikan. Bumi tidak semata-mata dilihat sebagai sesuatu yang bersifat material, melainkan sebagai sesuatu yang bersifat spiritual. Alam dan manusia sama-sama memiliki jiwa yang harus dihormati agar keberlangsungannya dapat terus mengalir seperti sungai kehidupan, menembus jarak dan waktu. Hidup adalah "mengikuti tatanan alam" dan "mengalir dalam aliran Tao" atau menurut ungkapan Taois "aku, langit dan bumi hidup bersama-sama, aku dan segala sesuatu adalah satu". ${ }^{13}$ Perbedaan tidak dipandang sebagai sesuatu yang dipertentangkan, melainkan sebagai sesuatu yang bertautan satu sama lain. "Aku" dan "Alam" adalah satu. Ekofeminisme menawarkan relasi yang nampak hirarkis namun harmonis, sebuah relasi yang menunjukkan perbedaan dalam kesatuan dan kesatuan dalam perbedaan. ${ }^{14}$ Ekofeminisme menggunakan pendekatan Tao untuk menolak segala bentuk konflik dan kekerasan di muka bumi ini atas alasan apa pun. ${ }^{15}$

Ekofeminisme berjalan dengan dua agenda besar. ${ }^{16}$ Pertama, agenda pada tataran konseptual dan filosofis untuk mendobrak cara pandang menindas yang selama ini berlaku umum yang belindung di

\footnotetext{
${ }^{11}$ Ratna Megawangi, Membiarkan Berbeda, cetakan pertama, (Bandung: Mizan, 1999), h. 9. Lihat Vandana Shiva \& Maria Mies, Ekofeminisme: Presfektif Gerakan Perempuan dan Lingkungan, h. 15, 374.

12Ruslani, ed., Wacana Spiritualitas Timur dan Barat, cetakan pertama, (Yogyakarta: Qolam, 2000), h. xii-xvi. Lihat pula Sukidi, Spiritualitas Feminis dalam Gerakan New Age, (Jakarta: Jurnal Perempuan, 2010), No. 20, h. 16.

${ }^{13}$ Alan Watt, The Tao of Philosophy, 1995, (USA: Turtle Publishing, 1995), h. 2425.

${ }^{14}$ Fritjof Capra, The Tao of Physics, An Exploration of the Parallels Between Modern Physics and Eastern, (London: Flamingo, 1991), h. xvi. Lihat juga, Albert Low, 2004, Zen Meditation, judul asli: Zen Meditation, alih bahasa: Khalid, (Yogyakarta: Saujana, 2004), cetakan pertama, h. 38-39.

${ }^{15}$ Ray Grigg, The Tao of Zen, (Boston: Charles R. Tuttle Co., 1994), h. xvi-xvii. h. $158-164$.

${ }^{16}$ A. Sonny Keraf, Etika Lingkungan Hidup, (Jakarta: Penerbit Kompas, 2010),
} 
balik sistem politik, ekonomi liberalisme dan ilmu pengetahuan yang Cartesian, mekanistik dan reduksionistik. Kedua, agenda pada tataran aksi, yaitu menentang institusi dan sistem sosial, ekonomi dan politik yang menindas melalui aksi nyata dengan memposisikan diri sebagai sebuah gerakan. Kedua agenda besar tersebut dijalankan ekofeminisme dengan antinaturalis atau antispesiesisme, konseptual, pluralistik, inklusif dan relasional dalam memandang manusia dan lingkungan hidup. Ekofeminisme dengan identitasnya tersebut menawarkan sebuah moralitas dan etika yang berbeda dengan etika klasik. Jika etika selama ini menitikberatkan pada hak, keadilan dan prinsip universal yang meneguhkan dominasi dan melanggengkan konflik kepentingan, maka ekofeminisme menawarkan etika matriarkal yang penuh dengan kasih sayang, kelembutan, kesalingan, kepedulian, dan cinta untuk menggantikan logika konflik, konfrontasi, kecurigaan dan dominasi. Etika ini digambarkan seperti kasih sayang seorang ibu terhadap anaknya.

Ekofeminisme sebagai antitesis atas cara pandang feminisme berjalan bersama dengan daya pikatnya masing-masing. Tarik-menarik antara model relasi gender yang menonjolkan dimensi patriarki atau maskulinitas dan model yang mengutamakan dimensi matriarki atau feminitas, mendorong penulis untuk mengemukakan sebuah rumusan baru yang merupakan sintesis dari kedua model tersebut. Sintesis tersebut penulis temukan pada model relasi gender yang dikemukakan Murata. Murata memberikan penghargaan tinggi terhadap keduanya, maskulinitas - feminitas; patriarki - matriarki. Murata menempatkan maskulinitas dan femnitas secara sejajar dan seimbang dalam sebuah hubungan kesatuan dan kesalingan. Keistimewaan pandangan Murata terletak pada keberhasilannya menampilkan sebuah prinsip kesatuan yang khas, yaitu kesatuan yang memecah diri menjadi dualitas (antara maskulinitas dan feminitas) kemudian memecah diri lagi menjadi pluralitas dan berwujud segala bentuk ciptaan Tuhan. Dualitas antara maskulinitas dan feminitas menjadi inti keberadaan dan keberlangsungan segala sesuatu, seperti makhluk yang memerlukan udara untuk dihirup dan dihembuskan atau seperti listrik dapat bekerja dengan adanya kutub positif-negatif. ${ }^{17}$

\section{Relasi Gender Murata}

${ }^{17}$ Annemarie Schimmel, Foreword, Sachiko Murata, The Tao of Islam: A Saurce Book on Gender Relationship in Islamic Thought, (New York: State University of New York Press, 2002), h. vii-x. 
Gender adalah sifat dan perilaku yang dibentuk secara kultural pada semua jenis kelamin, baik laki-laki maupun perempuan. Gender merupakan identitas yang telah membuat laki-laki dan perempuan menjadi terbedakan. Lebih dari itu, menurut Hum dengan mengutip pandangan Kate Millet dan Shulamith Firestone, gender telah membedakan struktur setiap aspek kehidupan masyarakat. Gender telah menjadikan laki-laki dan perempuan berbeda secara tajam karena masingmasing dikonstruksi sebagai lawan atas yang lain dan melalui pertentangan tersebut makin mempertegas dominasi laki-laki atas perempuan. Laki-laki dianggap sebagai jenis kelamin superior, sedangkan perempuan inferior. Pendekatan yang mengiringi pemaknaaan gender pun mengalami perkembangan pesat. Ada yang cenderung pada pendekatan sosial. Ada yang bersifat politis dan ada pula yang cenderung pada pendekatan biologis. ${ }^{18}$ Secara umum, benang merah dari seluruh pendekatan para feminis tersebut adalah pola rasionalnya yang mewarnai pandangan-pandangan mereka yang berkembang selama ini.

Murata menarik garis pembeda dari pola tersebut melalui pendekatan yang digunakannya dalam mendefinisikan gender. Murata berangkat dari sebuah keprihatinan terhadap realitas masyarakat Barat yang cenderung memandang negatif kedudukan perempuan Islam sehingga mendorongnya untuk membuat sebuah rumusan relasi gender baru. Rumusan ini diharapkan dapat mengubah pandangan yang kurang positif, terutama di kalangan mahasiswa yang diajarnya serta kolegakoleganya yang belum mengenal dengan baik tentang Islam. Pandangan negatif yang telah memasyarakat di kalangan Barat tersebut dianggap Murata sebagai pandangan yang telah berakar kuat sehingga sulit untuk diubah, kecuali melalui pendekatan baru yang lebih dapat diterima mereka. Meski demikian, pendekatan baru yang dibangunnya sama sekali tidak melanggar ketentuan baku yang berlaku selama ini. Rumusan baru tersebut berbasis spiritualitas yang merupakan hasil perpaduan pendekatan filsafat Tao Cina dan mistik Islam. Murata berharap upayanya ini dapat memberikan gambaran yang benar mengenai posisi perempuan dalam Islam. ${ }^{19}$

Murata memulai rumusannya dengan menempatkan kualitas sebagai sebuah kekuatan bahkan jati diri manusia dalam menjalankan misi sucinya dalam kehidupannya di muka bumi ini. Wujud dari kualitas

${ }^{18}$ Maggie Humm, Ensiklopedia Feminisme, h. 177-180.

${ }^{19}$ Sachiko Murata, The Tao of Islam: A Saurce Book on Gender Relationship in Islamic Thought, (New York: State University of New York Press, 1992), h. 1-2. 
tersebut dapat berupa spiritualitas yang merupakan upaya optimal manusia dalam mendekati Tuhannya. Kualitas dapat pula berupa perilaku dalam menjalankan hubungan horisontalnya baik dengan sesama manusia, maupun dengan alam.

Kualitas juga tercermin dalam pendefinisian Murata mengenai gender. Gender dipandangnya sebagai sebuah kualitas yang melekat pada seluruh manusia, baik laki-laki maupun perempuan. Pandangan Murata beriringan dengan definisi gender yang populer selama ini yang memandang gender sebagai sebuah sifat. Sampai pada titik tersebut seakan terdapat persamaan, tetapi jika dilakukan penelusuran lebih lanjut akan ditemukan perbedaan yang tajam. Jika feminis mendefinisikan gender sebagai sifat yang dilekatkan masyarakat kepada laki-laki dan perempuan $^{20}$, maka menurut Murata, gender merupakan sifat yang dilekatkan laki-laki dan perempuan pada dirinya sendiri sesuai usahanya dalam rangka menyempurnakan diri sebagai wakil Allah di muka bumi. Pandangan feminis mengenai gender bersifat kultural dan terberi (given), sedangkan pandangan Murata bersifat spiritual dan aktif ${ }^{21}$.

Murata mendefinisikan gender secara kualitatif sehingga relasi gender yang terbangun atas dasar kualitatif tersebut juga bersifat kualitatif. Bagi Murata, relasi gender tak lain adalah relasi kualitas. Kualitas yang dimaksudkannya adalah relasi kualitas maskulin dan feminin yang saling memiliki keterkaitan. Keterkaitannya berupa pertentangan (dualis), tetapi berada dalam hubungan kesatuan dan kesalingan (komplementer). Relasi gender yang dikemukakannya mengacu pada pandangannya tentang hakikat realitas yang tidak lain adalah Tuhan. Realitas bermula dari Tuhan dan akan kembali kepada Tuhan sehingga realitas sesungguhnya adalah Tuhan itu sendiri. Aktivitas manusia dan alam pun mengacu pada Tuhan yang tergambar melalui nama-nama-Nya, yaitu nama feminin atau yin/ jamal dan maskulin atau yang/ jalal. Maskulinitas dan feminitas Tuhan yang dualis juga tercermin pada alam dan manusia. Perbedaan yang terdapat pada Tuhan, alam dan manusia, tidak menjadikan ketiganya terpisah, melainkan menyatu dalam sebuah hubungan harmonis. Hubungan kualitas maskulin dan feminin

${ }^{20}$ Lihat Mansour Fakih, Analisis Gender dan Transformasi Sosial, (Yogyakarta: Pustaka Pelajar, 1997), cetakan kedua, h. 7-21.

${ }^{21}$ Maksud aktif dalam konteks ini adalah, bahwa apa dan bagaimana sifat yang akan melekat dapat diupayakan oleh manusia yang bersangkutan melalui olah jiwanya yang ditujukan kepada Tuhan. Bagaimana gender dapat dilihat pada: Sachiko Murata, The Tao of Islam, h. 18. 
yang terdapat pada manusia, alam dan Tuhan tersebut dikatakan sebagai sebuah relasi gender. ${ }^{22}$

Masalah relasi gender berkaitan erat dengan persoalan dualitas karena relasi yang terbentuk berupa relasi kualitas maskulin dan feminin. Perspektif dualis telah melahirkan pandangan tentang Tuhan yang bersifat dualis. Dualitas bermula dari Tuhan melalui nama-nama dan sifat-sifat-Nya kemudian menurun kepada ciptaan-Nya. Adanya penciptaan menunjukkan adanya dualitas-Nya karena telah terbedakan antara Tuhan sebagai Pencipta dengan entitas selain Tuhan sebagai ciptaan. Tuhan mencipta agar diketahui bahwa Ia berbeda dan bertentangan dari ciptaan-Nya. Tuhan adalah yang Nyata, sementara selain Dia tidak Nyata. Tuhan adalah yang/ jalal, sedangkan kosmos adalah yin/ jamal. Pencipta dapat dipahami melalui ciptaan, demikian pula sebaliknya. Tuhan juga dekat dalam waktu yang bersamaan karena Ia mencipta untuk menjalin hubungan yang dekat agar dikenali dan diketahui oleh ciptaan-Nya. Dualitas sifat-sifat-Nya tidak saja menyiratkan perbedaan, tetapi juga kesatuan dan kesalingan. DualitasNya melahirkan semua ciptaan sehingga dapat dikatakan, bahwa alam dan manusia merupakan manifestasi dualitas-Nya. Semua ciptaan berwujud dualitas-dualitas sehingga semuanya tidak dapat dipahami kecuali dalam kerangka dualitas. Kosmos penuh dualitas yang dilukiskan Murata sebagai yin/ jamal dan yang/ jalal dan di dalam dualitas selain terdapat perbedaan, pertentangan, kesatuan dan kesalingan juga terdapat hirarki. Hirarki bisa berupa adanya tingkatan, bahwa yang satu lebih tinggi dan yang lainnya lebih rendah atau yang satu lebih cerah dan yang lain lebih gelap. Tuhan Maha Mutlak dan kosmos relatif. ${ }^{23}$ Posisi Tuhan sebagaimana Tao merupakan sumber segala sesuatu. Dengan demikian segala suatu (jin/ jamal) dihasilkan dari Tao (yang/ jalal). Yang/ jalal di atas dan yin/ jamal di bawah. Ada hirarki yang tajam, tetapi secara bersamaan juga terdapat kesejajaran karena masing-masing menyatu dalam sebuah hubungan kesaligan (komplementer) Konsep kesatuan ini menjadi bagian penting dalam pembahasan tentang dualitas. ${ }^{24}$

Sifat maskulin (yang/ jala) Tuhan disejajarkan dengan ketakterbandingan Tuhan, sedangkan sifat feminin (yin/ jamal) disejajarkan dengan keserupaan Tuhan. Sifat feminim Tuhan dalam

${ }^{22}$ Murata, The Tao of Islam, h. 18.

${ }^{23}$ Murata, The Tao of Islam, h. 322.

${ }^{24}$ Ordier, Nirvana Tao, (New York: Inner Traditions Traditional Ltd., 1986), h.158. 
tradisi spiritual, lebih ditonjolkan daripada sifat maskulin karena menurut Murata, sifat belas kasih Tuhan kepada manusia dan seisi alam secara nyata mendahului kemurkaan-Nya. Sifat kefeminiman-Nya lebih nyata daripada kemaskulinan-Nya. Dominasi feminitas-Nya telah membuat semua makhluk juga seyogyanya menggunakan dimensi feminin dalam mendekati-Nya, yaitu dengan mempersembahkan kepasrahan total karena kepasrahan adalah manifestasi sifat feminin manusia terhadap Tuhan yang maskulin. Dalam konteks ini, ketika manusia berelasi dengan Tuhan, maka Tuhan diposisikan sebagai Dzat yang maskulin, sedangkan manusia sebagai hamba yang feminin. Feminitas merupakan sifat yang harus ditonjolkan manusia dalam berhadapan dengan Tuhan sebagaimana Tuhan menampilkan feminitasNya kepada manusia dan seluruh makhlukNya. ${ }^{25}$

Relasi gender adalah hubungan maskulinitas dengan feminitas yang terdapat dalam semua realitas. Relasi tersebut dapat digambarkan melalui bagan berikut ini:

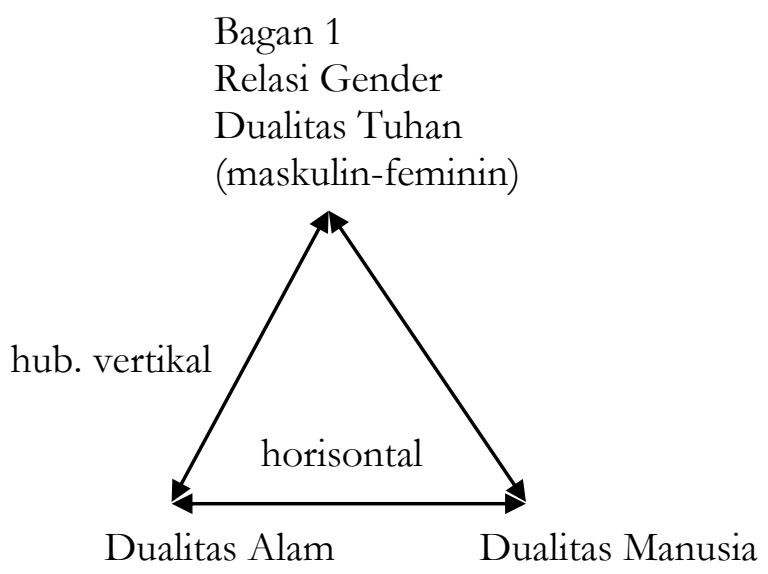

Segitiga menunjukkan relasi gender sebagai relasi kualitas maskulin dan feminin Tuhan yang dualis. Dualitas tidak saja berarti perbedaan yang meliputi: kontradiksi dan hirarki, tetapi juga meliputi pengertian kesatuan. Terdapat kesatuan dan kesalingan di dalam dualitas. Maskulinitas dan feminitas berbeda dan bertentangan, tetapi juga sekaligus merupakan satu kesatuan dan dalam hubungan kesalingan. Tuhan dengan selain Tuhan membentuk dualitas, demikian pula antara Tuhan dan alam, Tuhan dan manusia atau manusia dan alam. Garis-garis

${ }^{25}$ Murata, The Tao of Islam, h. 324. 
yang membentuk segitiga memperlihatkan perbedaan, kontradiksi, hirarki, sekaligus kesatuan dan kesalingan.

Tuhan dan alam disebut Murata sebagai makrokosmos dan manusia sebagai mikrokosmos. Ketiganya yang terangkum dalam makrokosmos dan mikrokosmos merupakan tiga realitas fundamental yang digambarkan Murata dengan tiga sudut dan garis yang saling berhubungan. Tuhan berada di sudut tertinggi, sementara manusia dan alam menempati dua sudut di bawahnya. Sudut teratas adalah Tuhan menjadi sumber bagi realitas lain. Alam dan manusia merupakan realitas derivatif dari realitas Tuhan. Pada segitiga terdapat sumbu vertikal dan horisontal. Sumbu vertikal menggambarkan adanya perbedaan antara Esensi Tuhan dan nama-nama-Nya, sementara sumbu horisontal mencerminkan adanya hubungan antara nama-nama Tuhan yang bersifat komplementer (saling melengkapi). ${ }^{26}$

Alam dan manusia sebagai tempat manifestasi disebut Murata sebagai "salinan". Makrokosmos dan mikrokosmos adalah salinan atau transkripsi dari keberadaan Tuhan, sedangkan antara alam dan manusia merupakan salinan satu sama lain. Meski alam dan manusia sama-sama sebagai salinan-Nya, manusia memiliki kedudukan yang lebih tinggi, yaitu sebagai salinan seluruh alam, sedangkan alam hanya salinan sebagian dari manusia. Manusia adalah "dunia serba meliputi" dan salinan dari kosmos karena Tuhan menjadikan manusia dari semua nama Tuhan. Manusia adalah ikhtisar (intisari) mulia dan agung yang di dalamnya terhimpun makna kosmos. Makrokosmos dan mikrokosmos dengan segala sifat kemajemukan memanifestasikan Tuhan dengan caranya masing-masing. Di sinilah bentuk pengistimewaan Tuhan kepada manusia sehingga wajar jika manusia diberikan amanah sebagai wakil Allah di muka bumi (khalifatullah). ${ }^{27}$

Murata membuat perbedaan pada sifat manusia dengan istilah "positif dan negatif'. Menurut Murata, sifat feminin dan maskulin manusia bisa positif, bisa pula negatif. Sifat maskulin atau feminin jika diterapkan secara salah, akan menjadi negatif. Oleh karena itu, jika kualitas feminin dan maskulin positif dapat ditegakkan, maka menurut Murata, manusia tersebut akan mampu menjadi individu yang sempurna. Kesempurnaan manusia bertolak dari usahanya yang kuat untuk menegaskan jati diri yang hakiki, yaitu kepasrahan kepada kehendak Tuhan. Manusia dapat menunjukkan keunggulan akal agar berhasil

${ }^{26}$ Murata, The Tao of Islam, h. 23.

${ }^{27}$ Murata, The Tao of Islam, h. 42. 
menggerakkan dirinya beralih dari potensialitas kepada aktualitas (aktualisasi akal secara penuh) dalam rangka memenuhi tugas sebagai wakil Tuhan dalam kosmos. Manusia dengan mengoptimalkan segenap keunggulannya, akan mampu melihat dirinya secara jernih dan seimbang karena manusia bagi Murata, tidak berbeda dengan Tuhan, yaitu manifestasi dari feminitas sekaligus maskulinitas. ${ }^{28}$

Feminitas dan maskulinitas aktual secara seimbang dalam diri manusia sebagaimana Tuhan semestinya juga dilihat secara seimbang oleh manusia. Seimbang berarti tidak dipandang hanya dari sisi maskulin atau feminin saja, melainkan keduanya. Tuhan sebagai Yang Maha Pengasih, Maha Cinta dan Maha Dekat sekaligus Tuhan Maha Berkuasa, Maha Kuat, Maha Hebat dan Maha Jauh. Sifat maskulin Tuhan ditampilkan dimaksudkan agar Tuhan tetap ditakuti manusia sehingga dapat menyempitkan ruang gerak dominasi kualitas negatif manusia. Murata beranggapan, bahwa seluruh sifat positif dapat diupayakan sebagaimana para spiritualis (dalam semua agama) telah menunjukkan perjuangan dan keberhasilan mereka dalam menegakkan sifat positif. Kaum Taois dan sufi menampilkan feminitas melalui ketundukkan dan kepasrahan total terhadap Tuhan. Kaum Taois dengan kekuatan femininnya dikenal sebagai penentang hegemoni maskulinitas dan hirarki sekaligus sebagai kelompok yang taat dan patuh terhadap peraturan yang berlaku di masyarakat. Kaum sufi menjalankan ritual thariqah (jalan ruhani dengan mendekatkan diri kepada Tuhan) bertujuan menghancurkan hirarki (secara spiritual) dan menampilkan sifat feminin, seperti keindahan dan kelembutan, terutama dalam hubungannya dengan Tuhan. Kaum spiritualis meskipun lebih menonjolkan feminitas, tetapi dalam kenyataannya, feminitas dan maskulinitas ditampilkan secara seimbang. Kekuatan manusia seperti akal memiliki dimensi kenabian dan kebenaran yang jika dioptimalkan dapat menghantarkan manusia menuju kesempurnaan. Akal beriringan dengan kebenaran sehingga menurut Murata, jika ada penolakan terhadap akal, berarti penolakan terhadap kebenaran. ${ }^{29}$

Penonjolan kualitas telah menjadikan istilah maskulin dan feminin tidak bermakna harfiah, melainkan bermakna batin. ${ }^{30}$ Maskulin dan feminin tidak mengacu pada jenis kelamin, melainkan kepada kualitas

${ }^{28}$ Murata, The Tao of Islam, h. 42.

${ }^{29}$ Murata, The Tao of Islam, h. 324-325.

${ }^{30}$ Annelen Simpkins \& Alexander Simpkins, Tao in Ten, (Boston: Tuttle Publishing, 2002), h. 41-42. 
yang menjadi ciri kesejatian manusia. Kedua kualitas tersebut dapat melekat pada semua manusia (semua jenis kelamin). Laki-laki bisa menjadi "perempuan" dan perempuan bisa menjadi "laki-laki". Keadaan dan kualitas yang sempurna sering dihubungkan Murata dengan "lakilaki" dan "perempuan". Murata mengemukakan dalam sebuah pandangannya, bahwa saat ini sangat sulit menemukan laki-laki dan perempuan sejati. Murata mengutip cerita tentang saudara perempuan Husayn Al-Hallaj (dari Najm Al-Din Razi) yang menutup setengah wajahnya dengan kerudung dan membiarkan sebagian wajahnya terbuka. Penampilannya tersebut mengundang seseorang bertanya: "Mengapa kamu tidak menutupi seluruh wajahmu?". Perempuan itu menjawab: "Tunjukkan padaku seorang laki-laki, maka akan ku tutupi seluruh wajahku. Kenyataannya, hanya ada separuh laki-laki (secara kualitas) di seluruh Bagdad ini dan itu adalah saudaraku sendiri Husayn Al-Hallaj. Kalau bukan karenanya, akan ku biarkan seluruh wajahku terbuka". ${ }^{31}$

\section{Penutup}

Relasi gender Murata dilatarbelakangi oleh Taoisme dan tradisi mistik Islam yang dipelajari Murata secara pribadi dan akademis. Konsep Tao yang menjadi dasar bagi kosmologi Cina dijadikan Murata untuk menjelaskan pandangannya tentang relasi gender. Alam digambarkan mengikuti kualitas Tao melalui prinsip yin dan yang yang menunjukkan kualitas aktif dan reseptif, laki-laki dan perempuan, maskulin dan feminin. Adapun tradisi mistik Islam yang dikenal Murata lewat Profesor Izutsu dan Nasr dipadukan dengan Taoisme untuk menjelaskan relasi gender Islam yang lebih bersifat spiritual. Pendekatan spiritual dipandang Murata sebagai pendekatan terbaik dan hakiki dalam memahami relasi gender dalam Islam.

Relasi gender bagi Murata adalah relasi kualitas maskulin (yang/ jalal) dan feminin (yin/ jamal) yang terdapat pada semua realitas, meliputi realitas Tuhan, manusia dan alam. Relasi yang terbangun bersifat dualis, yaitu pertentangan kualitas maskulin dan feminin yang melahirkan sebuah hubungan kesalingan dan kesatuan yang harmonis. Rumusan gender yang bertumpu pada Tuhan diposisikan Murata sebagai pusat realitas. Dualitas pada Tuhan terdapat pada nama-nama-Nya, sedangkan pada manusia dan alam tercermin dalam kualitas feminin dan maskulin yang melekat pada keduanya.

${ }^{31}$ Murata, The Tao of Islam, h. 326. 
Feminitas dan maskulinitas ditempatkan Murata secara setara karena keduanya dapat melekat pada semua jenis kelamin. Laki-laki dapat didominasi maskulinitas atau feminitas, dapat pula didominasi kedua kualitas tersebut secara seimbang, demikian pula perempuan. Laki-laki dan perempuan tidak dilihat Murata semata-mata pada jenis kelamin, melainkan lebih pada kualitas sebagaimana Tuhan melihat manusia. Lakilaki dan perempuan memiliki nilai yang sama sebagaimana kesamaan manusia dan alam. Perspektif spiritual Murata telah menempatkan gender pada posisi kesetaraan yang hakiki.

\section{DAFTAR PUSTAKA}

Budiman, Arif, 1983, Pembagian Kerja Secara Seksual, cetakan kedua, Gramedia, Jakarta.

Capra, Fritjof, 1991, The Tao of Physics, An Exploration of the Parallels Between Modern Physics and Eastern, Flamingo, London.

Descartes, Rene, 1962, Discourse on Methode, The Opera Court Publishing Company, Chicago.

Fakih, Mansour, 1997, Analisis Gender dan Transformasi Sosial, cetakan kedua, Pustaka Pelajar, Yogyakarta.

Grigg. Ray, The Tao of Zen, 1994, Charles R. Tuttle Co., Boston.

Harsono, Rebeka, 2006, Gerakan Perempuan: Antara Kepentingan Perempuan dan Politik Gender, dalam: Irwan Abdullah, ed., Sangkan Paran Gender, Pustaka Pelajar, Yogyakarta.

Heroepoetri, Arimbi, \& R. Valentina, 2004, Percakapan tentang Feminisme vs Neoliberalisme, cetakan pertama, debtWATCH Indonesia - Institut Perempuan, Jakarta.

Humm, Maggie, 2003, Ensiklopedia Feminisme, judul asli: "Dictionary of Feminist Theory" alih bahasa Mundi Rahayu, cetakan pertama, Fajar Pustaka Baru, Yogyakarta.

Ihromi, Tapi Omas \& Luhulima, Achie S.,ed., 2003, Hak Azazi Perempuan, Jakarta, Convention Watch, Pusat Kajian Wanita dan Gender UI \& Yayasan Obor Indonesia, Jakarta.

Illich, Ivan, 1998, Matinya Gender, judul asli: Gender, alih bahasa: Omi Intan Naomi, cetakan pertama, Pustaka Pelajar, Yogyakarta. 
Keraf, A. Sonny, 2010, Etika Lingkungan Hidup, Penerbit Kompas, Jakarta.

Low, Albert, 2004, Zen Meditation, judul asli: Zen Meditation, alih bahasa: Khalid, cetakan pertama, Saujana, Yogyakarta.

Megawangi, Ratna, 1999, Membiarkan Berbeda, cetakan pertama, Mizan, Bandung.

Moore, Harietta L, 1988, Feminism and Antropology, Politiy Press, Cambridge.

Murata, Sachiko, 1992, The Tao of Islam: A Saurce Book on Gender Relationship in Islamic Thought, State University of New York Press, New York. , 2000, Chinese Gleams of Sufi Light, State University of New York Press, New York.

Nugroho, Riant, 2008, Gender dan Strategi Pengarus-utamaannya di Indonesia, cetakan pertama, Pustaka Pelajar, Yogyakarta.

Ordier, Daniel, 1986, Nirvana Tao, Inner Traditions Traditional Ltd., New York.

Ridjal, Fauzi, dkk. ed., 1993, Dinamika Gerakan Perempuan di Indonesia,cetakan pertama, Tiara Wacana, Yogyakarta.

Ruslani, ed., 2000, Wacana Spiritualitas Timur dan Barat, 2000, cetakan pertama, penerbit Qolam, Yogyakarta.

Shiva, Vandana \& Mies, Maria, 2005, Ekofeminisme: Presfektif Gerakan Perempuan dan Lingkungan, judul asli: Ecofeminsme, alih bahasa: Kelik Ismunanto dan Lilik, cetakan pertama, IRE Press, Yogyakarta.

Simpkins, Annelen \& Alexander Simpkins, 2002, Tao in Ten, 2002, Tuttle Publishing, Boston.

Schimmel, Annemarie, 2002, Foreword, Sachiko Murata, The Tao of Islam: A Saurce Book on Gender Relationship in Islamic Thought, State University of New York Press, New York.

Sukidi, 2010, Spiritualitas Feminis dalam Gerakan New Age, Jurnal Perempuan, No. 20, Jakarta.

Watt, Alan, 1995, The Tao of Philosophy, 1995, Turtle Publishing, USA.

Wolf, Naomi, 1997, Gegar Gender, judul asli: Fire With Fire, alih bahasa: Omi Intan Naomi, cetakan pertama, Pustaka Semesta Press, Yogyakarta. 
